\title{
Editorial
}

\section{Profiting from Antarctic science}

$\mathrm{T}$ his is apparently the age of innovation, impact and application. No longer is it enough to seek to discover and understand. In the 21 st century science has to have application and influence. The British Government has made it clear that every researcher who gains a grant of public money has to say what impact the research will have and consider its commercial uses. If you work in agricultural research or chemical engineering this is surely not too difficult, but for fields like astronomy or Antarctic research the options are rather limited, which makes the recent addition of an Innovation Centre to British Antarctic Survey seem rather odd. Indeed, with the Research Excellence Framework being applied yet again to British universities to predetermine how research money will be given out, this government is clearly obsessed with measureable targets, tightly focussed impacts and economic returns.

Science, including that from Antarctica, has been commodified for some time now with governments becoming increasingly interested in setting the goals and looking for economic returns. In this, and in their preoccupation with simplified impact measures, they increasingly resemble commercial companies for whom the only important output is profit rather than knowledge. In the United Kingdom the science community has been deliberately placed within the Department for Business rather than Education to ensure that Research Councils and universities do not lose sight of the principal objective - money.

It is not only the British who want to see returns on their research investments. The world in general is in thrall to market forces. New Zealand is beginning to rely on non-government funding for research through its new Antarctic Research Institute, whilst at least 25 countries are now trying to get bioprospecting to pay off through patents or the marketing of new products derived from Antarctic materials. Although the Protocol on Environmental Protection bans mineral exploitation for at least 50 years there are increasingly strident remarks from some Consultative Parties (and others who would like to be Consultative Parties) about researching the possible future bonanza from Antarctic mineral resources. In the Southern Ocean the interest in krill harvesting increases every year with growing sales of krill oil as a health food, pelleted krill for fish farms and chitin, enzymes and lipids as specialist products.

How will all this work in terms of the greater goals of understanding our world and managing it sustainably for future generations? How will this approach ensure that the best ideas are funded, that the most useful long-term data are collected and those that think outside of the box are given a chance? Last year the British physicist Peter Higgs was feted around the world and given a Nobel Prize for his prediction of the Higgs boson, recently discovered in experiments at CERN. Back in the 1960s he had the opportunity to develop the paradigms that challenged existing thinking without having to justify the impact in advance, suggest applications for his new theory or worry that he was likely to be sacked if he failed to score sufficient citations. These days he would be lucky to get past the first round of grant assessment.

Although this has focussed on the United Kingdom the government patterns are repeated elsewhere. It is clear that Antarctica is a key driver of many global processes and provides a unique platform to measure change and assess trends in a rapidly changing world. Antarctic research is thus not a luxury but a necessity if we are to prepare adequately for the future. Antarctic commercialisation seems an unwanted distraction when understanding the processes is surely key to predicting our long-term survival.

D.W.H. WALTON 